\title{
Pulmonary vein isolation in the treatment of atrial fibrillation
}

This article was published in the following Dove Press journal:

Research Reports in Clinical Cardiology

2 May 2016

Number of times this article has been viewed

\author{
Saurabh Kumar \\ Gregory F Michaud \\ Cardiac Arrhythmia Service, \\ Cardiovascular Division, Brigham and \\ Women's Hospital, Boston, MA, USA
}

Correspondence: Gregory F Michaud Cardiac Arrhythmia Service, Cardiovascular Division, Brigham and Women's Hospital, 75 Francis St, Boston, MA - 02115, USA Email gfmichaud@partners.org

\begin{abstract}
Atrial fibrillation (AF) is the commonest arrhythmia in humans and is associated with marked reduction in quality of life and an elevated thromboembolic risk. Paroxysmal, persistent, and permanent forms of AF have been recognized. Whilst antiarrhythmic drugs are considered as first-line therapy, the role of catheter ablation is increasing due to its superior efficacy in terms of quality of life and reduction in AF burden. The central paradigm for catheter ablation of $\mathrm{AF}$ is that triggers for AF are located near and within the pulmonary veins (PVs), and electrical isolation of the PVs from the left atrium forms the cornerstone of most catheter ablation strategies. Whilst paroxysmal form is generally trigger dependent, persistent and permanent forms are associated with variable interaction between triggers and "substrate" comprised of atrial and PV electrical and structural remodeling. Nevertheless, isolation of the PVs still forms a critical component of catheter ablation strategies, regardless of AF type. Procedural efficacy, however, is limited by PV conduction recovery. This is likely due to deficiencies in ablation tools or limitations of intraprocedural assessment of lesion efficacy. Careful attention to surrogates of tissue heating, such as impedance decrease and electrogram morphology changes, along with advances in catheter technology like contact force catheters may improve rates of durable PV isolation and single-procedural success. This review discusses the mechanism of paroxysmal AF with particular focus on the role of the PVs in AF initiation and PV isolation in the management of AF.
\end{abstract}

Keywords: contact force, lesion transmurality, radiofrequency catheter ablation, paroxysmal atrial fibrillation, electrophysiology, AF

\section{Introduction}

Atrial fibrillation (AF) is the most prevalent cardiac arrhythmia in humans. ${ }^{1}$ Several randomized trials and meta-analyses have demonstrated the superiority of catheter ablation compared to antiarrhythmic drugs or rate-control agents in terms of AFfree survival. Isolation of the pulmonary veins (PVs) has become the cornerstone of catheter ablation for prevention of AF. ${ }^{2}$ Although several energy sources are either available or being investigated for catheter ablation, radiofrequency (RF) energy and cryoablation are the main sources. The purpose of this review is to summarize the contribution of the PVs to AF maintenance, and to review pertinent aspects of PV electrophysiology that contribute to AF. Furthermore, we examine the critical role of pulmonary vein isolation (PVI) by percutaneous RF catheter ablation in the management of AF, remaining focused on paroxysmal AF alone. A detailed discussion about the mechanism of persistent AF is beyond the scope of this review and is discussed elsewhere. ${ }^{3-8}$ The current discussion also focuses 
on use of RF energy alone; the use of endoscopic ablation systems and "single-shot" devices is discussed in detail elsewhere. $^{9}$

\section{Epidemiology of AF}

The prevalence of AF doubles with each decade over the age of 55 years, independent of known preexisting conditions, occurring in $0.1 \%$ in those under 55 years of age, and increasing to $9.0 \%$ in those aged over 80 years. ${ }^{10}$ The lifetime risk of developing AF is $\sim 25 \%$ in those who have reached the age of $40 .{ }^{11}$ AF is a rapidly growing epidemic with a projected prevalence of 5.6 million by 2050 in the USA alone. ${ }^{1}$ AF is associated with significant impairment in quality of life, with a four- to fivefold increase in the risk of stroke, a doubling of risk for dementia, tripling of the risk of heart failure, and $40 \%-90 \%$ increased risk of mortality. ${ }^{12}$ Furthermore, AF is also a costly public health problem with hospitalization as the primary cost driver. ${ }^{13}$ Costs are strongly influenced by the number of arrhythmia recurrences, with 1-2 recurrences of paroxysmal AF costing US\$6,331 and $\geq 3$ recurrences costing US\$10,312. ${ }^{14}$

\section{Type of AF}

Broadly, three types of AF are recognized: ${ }^{15}$ 1) paroxysmal AF (self-terminating episodes usually within 48 hours but lasting $<7$ days), 2) persistent (episodes lasting $>7$ days and requiring electrical or pharmacological reversion) or long-standing persistent (AF lasting 1 year and a rhythm control strategy is adopted), and 3) permanent AF (in which cardioversion failed or was not attempted due to patient or physician preference). When paroxysmal AF occurs in the absence of structural heart disease or clinical risk factors for AF, it is often termed "lone AF". The distinction between different forms of AF is of particular relevance to the underlying mechanism and likelihood of success of catheter ablation. Whilst "triggers" located in the PVs drive paroxysmal AF, the conventional paradigm is that persistent and permanent forms are associated with atrial electrical and structural remodeling predicated by underlying atrial fibrosis and maintained by spatially disorganized mechanisms. Recently, there has been significant interest in the hypothesis that AF may be initiated and/or maintained by localized "rotors" and focal sources that are not necessarily constrained to the PVs are bi-atrially distributed (even in paroxysmal AF), and can be targeted with focal ablation in an attempt to improve outcomes. ${ }^{16} \mathrm{~A}$ detailed discussion of the ongoing research on this topic is beyond this review and is covered in detail elsewhere. ${ }^{7}$
Persistent and permanent forms of AF are often associated with structural heart disease and clinical risk factors for AF. The classification also has some predictive clinical value in that paroxysmal AF is more amenable to rhythm control using catheter ablation. ${ }^{17}$ Furthermore, success rates of catheter ablation are highest for lone AF but fall with increasing persistence, comorbidities, and presence of structural heart disease. ${ }^{18}$

\section{Role of the PVs in AF}

Whilst anatomic studies had shown that atrial myocardium extends into the PVs many years ago, ${ }^{19}$ the importance of this finding was not recognized until the seminal work by Haïssaguerre et al. ${ }^{2}$ Their study was the first to highlight the importance of the PVs as an important source of triggers that initiate AF. The authors demonstrated that repetitive activities with a very short cycle length were localized to 2-4 cm within the PVs and that these could act as the initiating triggers of paroxysmal AF. Furthermore, targeted RF ablation of these foci could effectively treat AF in $62 \%$ of patients. ${ }^{2}$ Since then, there has been repeated confirmation of the key role of the PVs; however, a clear understanding of the underlying mechanisms has remained elusive. ${ }^{17}$

\section{Arrythmogenicity of the PVs: lessons from bench studies}

Studies in isolated PV preparations have demonstrated that abnormal automaticity, triggered activity, and reentry may all occur under certain circumstances (Figure 1). 2,17,20,21 The arrhythmogenic source of PV triggers is thought to exist within a sleeve of myocardial tissue extending from the left atrium (LA) onto the anatomical PVs.

There is conflicting evidence as to whether specialized pacemaker-type cells capable of automaticity are present within PV myocytes. Whilst some studies have shown atrioventricular (AV) nodal-like cells or cells that express markers that belong to the conduction system, this has not been definitively proven in human studies. ${ }^{3} \mathrm{PV}$ myocytes have a larger density of slow delayed rectifier current $(I \mathrm{Ks})$, and rapid delayed rectifier current $(I K r)$; they also have a lower density of transient outward current (Ito) and L-type calcium current $(I \mathrm{CaL})$ than atrial tissue. PVs thus have a more depolarized resting membrane potential, and shorter duration action potential with a slower upstroke velocity, factors implicated in a larger propensity for reentry. ${ }^{22}$ These studies have shown that PVs exhibit absence of automaticity, spontaneous diastolic depolarisations or after-depolarisations.

In contrast, PVs can show spontaneous activity with unusual and heterogeneous action potential morphologies, and 


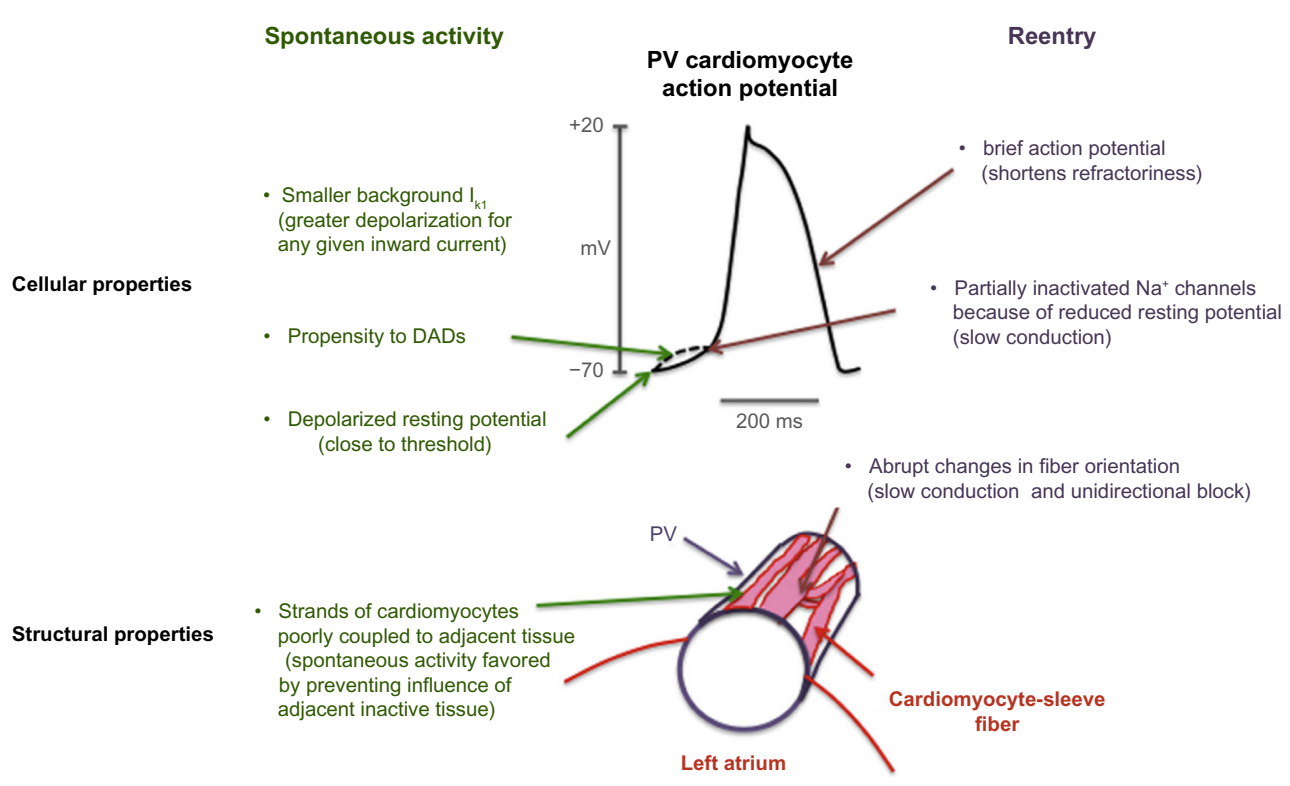

Figure I Putative mechanisms of paroxysmal atrial fibrillation attributed to properties of the pulmonary vein (PV) cardiomyocyte and PV-left atrium architecture. Notes: The figure shows potential cellular (top) and structural abnormalities (bottom) that contribute to automaticity (left) and reentry (right). Reprinted from Canadian Journal of Cardiology, 29(10), Nattel S, Paroxysmal atrial fibrillation and pulmonary veins: relationships between clinical forms and automatic versus re-entrant mechanisms, II47-I I49, Copyright (C) 2013, with permission from Elsevier. ${ }^{17}$

Abbreviations: DAD, delayed after-depolarization; IKI, inward-rectifier potassium current.

the presence of increased early and late after-depolarizations particularly during sympathomimetic conditions. ${ }^{23}$ In some studies, the response of $\mathrm{PV}$ activity to adenosine is more consistent with a reentrant than a focal ectopic type of mechanism..$^{24,25}$

\section{Anatomic basis for PV arrhythmogenicity}

The complex anatomy of the PVs and the PV-LA junction also provides the perfect anatomic substrate, promoting unidirectional block, slowed conduction, fractionation, and anisotropy - key elements that promote reentry within and around the PVs. ${ }^{21}$ In the literature, there are several distinctive anatomical features of this region that have been recognized including: 1) circumferential bundle of muscular sleeves encircle the PV ostium; ; ${ }^{19,26,27}$ 2) multiple layers of branching fibers from multiple complex connections at the PV-LA junction; 3) abrupt changes in fiber orientation; 4) thicker muscle sleeves at the PV-LA junction, especially at the intervenous ridge that tend to taper off distally; ${ }^{19,26,27} 5$ ) longer muscular sleeves in the superior veins than in the inferior veins; ${ }^{28}$ and 6) a high density of epicardial ganglionated subplexus located in the inferior portions of the PVs which are thought to play an important role in the autonomic modulation of PV triggers..$^{29,30}$ Abrupt changes in PV fiber orientation promote unidirectional block and slow conduction within the PVs. ${ }^{21}$

\section{Arrhythmogenicity of the PVs: lessons from electrophysiologic studies}

Jaiis et al characterized the electrophysiological properties of $\mathrm{PVs}$ in patients with paroxysmal AF in comparison to controls without $A F^{31} \mathrm{AF}$ patients had shorter venous effective refractory periods (ERPs) compared to the LA ERPs, whereas in controls, PV ERPs were longer than the LA ERPs. Venous ERPs and functional refractory periods in AF patients were shorter than controls whereas LA ERPs were not significantly different. The PVs of AF patients demonstrated pronounced decremental conduction, with AF inducibility more likely when pacing from within the PVs than the LA. The authors postulated that long conduction times in PVs combined with short ERPs and functional refractory periods provide a very favorable milieu for reentry in or around the veins, thus serving as a substrate for $\mathrm{AF}$ maintenance. Whilst the PVs are thought to possess necessary substrate for reentry, the PVs are highly susceptible to electrical remodeling with short episodes of $\mathrm{AF}^{32,33}$ In their study, 15 minutes of AF induced from within the PVs in patients with no history of AF resulted in significant shortening of refractoriness, marked conduction delays, and an increased number of secondary episodes of AF. In fact, the extent of electrical abnormalities in the PVs was more pronounced than the LA, suggesting that "AF begets AF" in the PVs.

Teh et al extended this work by characterizing the electroanatomical substrate of the PVs in patients with paroxysmal 
and persistent AF in the absence of structural heart disease compared to controls without AF. ${ }^{33}$ Compared to controls, the PVs of patients with AF had lower mean voltage, a higher percentage of low voltage areas, and shorter PV muscle sleeves. AF patients had shorter ERPs, slower conduction, and more prevalent complex signals compared to controls. Patients with persistent AF had even more marked changes, with a higher percentage of low voltage, slower conduction, and more complex signals compared to paroxysmal AF patients. These findings suggested the development of a progressive electroanatomical substrate in AF patients from an underlying fibrotic process or increased heterogeneity of muscle distribution within the PVs. This fibrotic substrate could facilitate arrhythmogenesis through heterocellular-gap junctional coupling of myofibroblasts with adjacent myocytes causing electrotonic modulation of conduction. ${ }^{34}$

Lee et al performed high-density mapping of the right superior PV-LA junction in humans undergoing cardiac surgery to characterize the electrophysiologic properties of this region that appears critical for AF sustenance. ${ }^{35}$ The authors found that pacing produced a line of functional delay and block at the PV-LA junction preceded by significant increases in conduction slowing, the appearance of double potentials, and fractionated electrograms. Decremental conduction during programmed electrical stimulation resulted in circuitous activation patterns at the PV-LA junction, creating the substrate for reentry or result in wavebreak and fibrillatory conduction in the presence of PV focal discharge. ${ }^{35}$ During conditions of atrial stretch (eg, heart failure, mitral regurgitation), which is an important trigger for AF, the PV-LA junction exhibited electrophysiological changes predisposing to reentry, such as exaggeration of conduction slowing, alongside significant increase in fractionated electrograms with increasingly premature extrastimuli. ${ }^{36}$

Stiles et al showed that the electrical and structural changes seen in the PVs in patients with paroxysmal AF also occur in the atria; these authors showed widespread atrial abnormalities in patients with paroxysmal lone AF remote from episodes of AF. ${ }^{37}$ AF patients had marked structural abnormalities characterized by atrial dilatation and lower mean bi-atrial voltage suggesting loss of atrial myocardium. There were also marked bi-atrial conduction abnormalities, including prolongation of conduction times, slower conduction velocity, site-specific conduction delay at the crista terminalis, increased proportion of complex electrograms, prolonged $\mathrm{P}$-wave duration, and sinus-node dysfunction in AF patients compared with controls. This study demonstrated that, aside from the arrhythmia itself, patients with paroxysmal lone AF have an abnormal atrial substrate characterized by structural change and conduction slowing that may predispose to $\mathrm{AF}$ episodes.

\section{Autonomic influences on PV arrhythmogenicity}

The autonomic nervous system also plays a critical role in paroxysmal AF. ${ }^{38}$ The PVs and PV-LA junction are richly innervated with autonomic nerves. This includes clusters of autonomic ganglionated plexi (GPs), located in specific epicardial fat pads and within the ligament of Marshall. ${ }^{39}$ A dynamic relationship between the parasympathetic and sympathetic nervous system plays a critical role in the initiation of AF. AF onset can be preceded by altered autonomic activity or change in autonomic balance rather than increase sympathetic or parasympathetic drive alone. ${ }^{40,41}$ Studies have reported a primary increase in adrenergic activity followed by marked vagal activity immediately prior to the onset of paroxysmal AF. ${ }^{38}$ Vagal activity enhances the acetylcholinedependent potassium channels, shortening action potential duration and stabilizing and accelerating reentrant rotors. ${ }^{42,43}$ Moreover, the stereotypical predominance of AF-maintaining sources for the LA in patients with paroxysmal AF is explained by the larger potassium current densities found in left versus right atrial cardiomyocytes responsible for the left-to-right frequency gradient of activation found in this subset of patients. ${ }^{44}$

Sympathetic stimulation increases diastolic calcium leak and promotes delayed after-depolarization-induced ectopic firing. ${ }^{45}$ Gould et al demonstrated evidence of heightened atrial sympathetic innervation in the right atrial appendage of persistent AF patients compared to controls undergoing bypass surgery, suggesting autonomic remodeling as part of the atrial substrate for AF maintenance. ${ }^{46}$ Animal models of rapid atrial pacing and heart failure have noted that $\mathrm{AF}$ onset is preceded by simultaneous sympathovagal discharges. ${ }^{47}$ Autonomic neural remodeling contributes to positive feedback loops that are thought to be essential for AF persistence and recurrence; remodeling of this sort may predispose AF to sustain itself in the first few hours. ${ }^{48}$

In ablation studies, focal firing within the PVs is often eliminated by ablation, potentially suggesting that interruption of the nerves from the ganglionic plexus to the PVs may have a role in the success of PVI procedures. ${ }^{49,50}$ Indeed, a recent randomized study showed that recurrent atrial arrhythmias was significantly lower when ganglionic plexus ablation was combined with PVI compared to PVI alone in 248 patients randomized to either circumferential PVI 
$(n=78)$, anatomic ablation of the main left atrial ganglionated plexus (GP) $(n=82)$; or circumferential PVI followed by anatomic ablation of the main left atrial GP $(n=82) .{ }^{51}$ It is also plausible that axonal regeneration may contribute to late recurrence of $\mathrm{AF}^{39}$

\section{Isolation of the PVs as the cornerstone of catheter ablation of AF}

Since the seminal observation by Haïssaguerre et al, there has been a dramatic increase in the number of catheter ablation procedures for AF worldwide. ${ }^{52}$ Indeed, current AF guidelines state that catheter ablation should be considered as first-line treatment for the treatment of symptomatic, drug-refractory paroxysmal AF. ${ }^{39}$ This procedure involves proximal circumferential PV isolation not only of the underlying arrhythmia mechanism ${ }^{2}$ but also of the potential "substrate" for reentry at the PV-LA junction, including modification of autonomic nervous system (Figure 2). ${ }^{39}$ The wide antral lesion set may also encompass less common trigger sites for AF including the ligament of Marshall and the posterior LA wall as well as reducing the mass of atrial tissue needed to sustain reentry in and around the PV-LA junction.

A randomized trial showed superiority of a large circumferential lesion set around both ipsilateral PVs with verification of conduction block as being more effective treatment of AF than segmental isolation. ${ }^{53} \mathrm{~A}$ meta-analysis of 12 trials including $\sim 1,200$ patients concluded that a wide antral approach is more effective than ostial PVI in achieving freedom from total atrial tachyarrhythmia recurrence at long-term follow-up; however, this analysis included patients with paroxysmal and persistent $\mathrm{AF}^{54}$ These findings are also

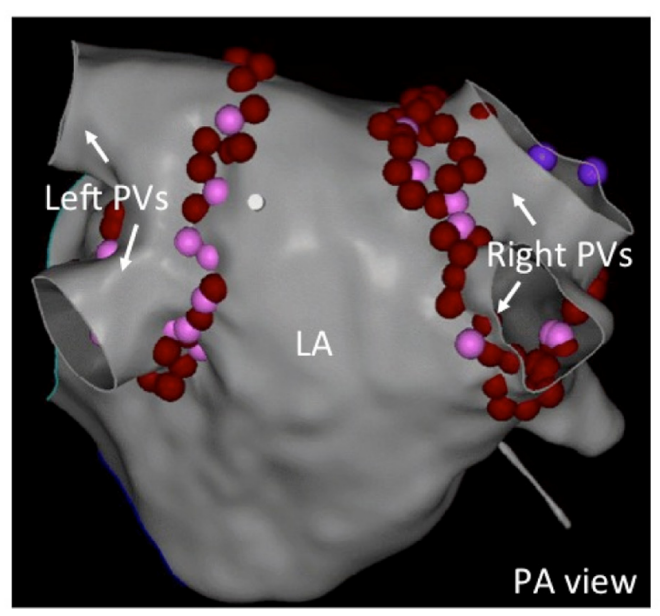

Figure 2 A typical wide antral lesion set (red and pink dots) in the left atrium (LA). Note: Purple dots represent sites of phrenic nerve capture.

Abbreviations: AP, antero-posterior view; LAA, left atrial appendage; PA, postero-anterior view; PV, pulmonary vein.

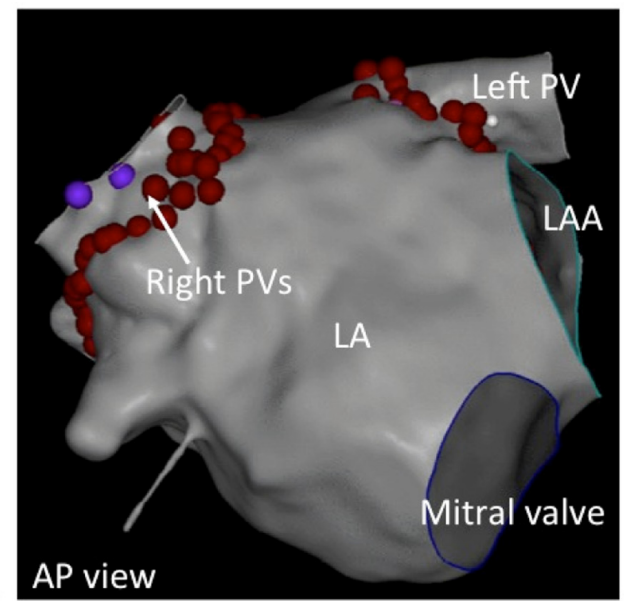

consistent with the observation that the size of the isolated left atrial area correlated with significantly lower recurrence of AF and macroreentrant tachycardias after PVI for paroxysmal AF. ${ }^{55}$

$\mathrm{PV}$ isolation remains critical not only for paroxysmal AF but also as part of the initial ablation strategy in persistent and long-standing persistent AF. ${ }^{56}$ In a meta-analysis of 46 persistent AF ablation studies comprising 3,800 patient outcomes (defined as AF recurrence, compared to medical therapy) were better if the PVs were encircled (odds ratio 0.26 ); electrical isolation compared with purely anatomic encirclement significantly reduced AF recurrence (odds ratio 0.33$).{ }^{56}$

Several randomized trials ${ }^{57-60}$ and meta-analyses of randomized and nonrandomized studies ${ }^{57,61-63}$ over the past decade have demonstrated the superiority of catheter ablation in terms of AF-free survival $(\sim 71 \%)$ compared to antiarrhythmic drugs or rate-control agents alone $(\sim 52 \%)$. Importantly, AF-free survival is maintained over long-term follow-up ( $\sim 5$ year) in the vast majority of patients with paroxysmal AF $(63 \%-80 \%)$ with a low incidence of progression to chronic AF $(\sim 2 \%)$, however, necessitating multiple procedures. ${ }^{57,64-68}$

Some proponents argue for earlier ablation in patients with paroxysmal AF to prevent progression to persistent forms, which is typically associated with the presence of structural heart disease or cardiomyopathies. ${ }^{69}$ Catheter ablation has also been shown to be superior to antiarrhythmic drugs with improvement in quality-of-life scores relative to baseline, alongside restoration to levels at or above population norms. ${ }^{58-60}$ One randomized trial comparing the efficacy of catheter ablation with antiarrhythmic drugs as first-line 
treatment in patients with paroxysmal AF found no significant difference between the two groups. However at 24 months, freedom from AF, burden of AF, and physical well-being were significantly better in the ablation group compared to the drug therapy group..$^{70} \mathrm{~A}$ recent meta-analysis also suggested the beneficial effect of catheter ablation both as a first-line (relative risk 0.52) and as a second-line (relative risk 0.3) therapeutic modality for patients with $\mathrm{AF}^{71}$

Complete electrical disconnection of the PVs from the LA is an important electrophysiological end point responsible for achieving reliable control of this arrhythmia. ${ }^{39,72,73}$ Lee et al elegantly demonstrated the critical role of durable PVI in the maintenance of sinus rhythm by examining patients undergoing double lung transplantation where a "cut and sew" PV antral isolation analogous to a catheterbased approach is performed as part of the transplantation procedure. The authors followed double with single lung transplant versus non-transplant thoracic surgery patients for a period of $\sim 5$ years, showing that double, but not single, lung transplant provided long-term freedom from AF. Only $0.5 \%$ of the double lung versus $12.6 \%$ of the single lung transplant versus $11.4 \%$ of the nontransplant in thoracic surgery patients developed AF recurrence in follow-up, demonstrating the critical role of the $\mathrm{PV}$ in the pathogenesis of AF and the importance of durable PV electrical isolation as the cornerstone in strategies for the long-term prevention of $\mathrm{AF}^{74}$ The end point for PVI is generally accepted to be elimination (or dissociation) of the PV potentials recorded from either one or two circular mapping catheters or a basket catheter within the ipsilateral PVs (Figure 3), and/or exit block from the PVs. ${ }^{39}$

In contrast to the aforementioned data, some recent studies have questioned whether empiric isolation of all four PVs is necessary for successful catheter ablation of paroxysmal AF. $^{75,76}$ Dixit et al ${ }^{75}$ showed that isolation of arrhythmogenic veins was as efficacious as empiric isolation of all veins in achieving long-term AF control. Using a different approach, Atienza et $\mathrm{al}^{76}$ found that an ablation strategy aimed a targeting high dominant frequency sites was noninferior to circumferential PV isolation in achieving freedom from atrial tachyarrhythmias at 1 year despite shorter delivered ablation time and fewer isolated veins. Jiang et al found no difference in the incidence of reconnected PVs in patients without AF recurrence who underwent repeat LA mapping compared to those patients who underwent repeat left atrial mapping for AF recurrences after PVI. ${ }^{77}$ Furthermore, emerging data focused on elucidating the triggering and sustaining mechanisms for AF beyond the PVs have shown the existence of organized reentrant circuits (rotors) or focal impulses that are not necessarily constrained to the PVs, are bi-atrially

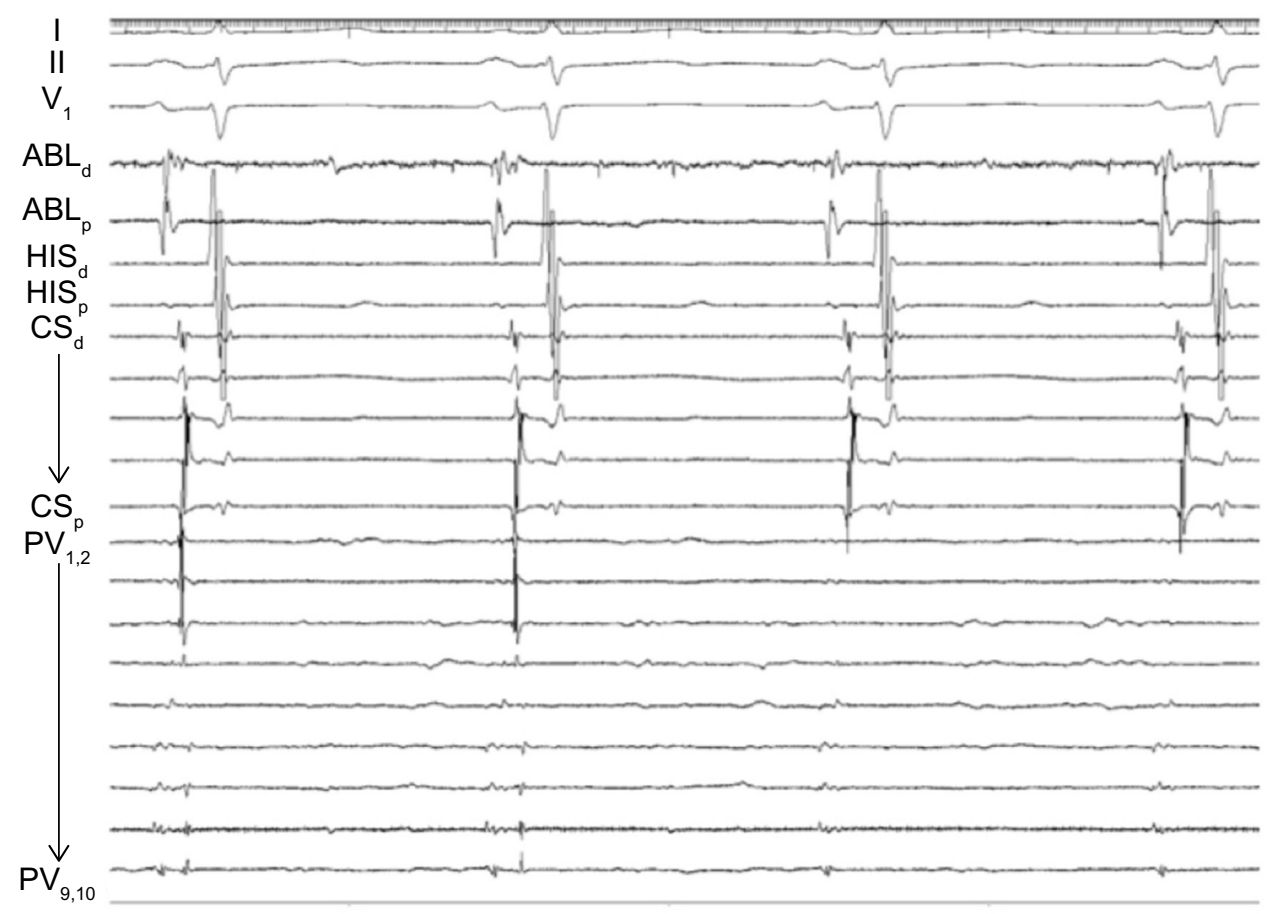

Figure 3 Example of electrical isolation of the pulmonary veins $(P V s)$ as measured by the circular mapping catheter $\left(P V_{1,2}\right.$ to $\left.P V_{9,10}\right)$.

Note: There is an acute loss of PV signals from the second to the third beat in the image.

Abbreviations: ABL, ablation catheter; CS, coronary sinus catheter; distal pole; ${ }_{p}$, proximal pole. 
distributed in paroxysmal AF, and can be targeted with focal ablation in an attempt to improve outcome. ${ }^{7}$ Further work is needed before a shift in acceptance of the paradigm notion that isolation of PVs is critical to the success of catheter ablation for paroxysmal AF.

\section{The importance of electrical reconnection between the PVs and the LA}

Although electrical disconnection can be achieved almost universally by the end of the procedure, long-term efficacy of catheter ablation remains modest, with single- and multiple-procedure success rates of $54 \%$ and $79 \%$, respectively, recently reported for paroxysmal AF over longterm follow-up ( $\geq 3$ years). ${ }^{78}$ Most patients will require 1-2 procedures (mean 1.2 procedures) to achieve reasonable efficacy. ${ }^{67}$ The chief reason for this is recovered PV-to-LA conduction. ${ }^{39,67}$

Many studies have shown the time-dependent inevitability of PV conduction recovery and its relationship to future AF recurrence. Up to $50 \%-64 \%$ of PVs reconnect during an intraprocedural waiting period of up to 60 minutes after initially isolating the PVs. ${ }^{79-81}$ Studies in which patients with AF recurrence were studied on second or subsequent procedures have shown that AF recurrence post-catheter ablation is usually associated with resumption of PV-LA conduction. ${ }^{72,73,82}$

\section{Importance of non-PV triggers in recurrence of $A F$}

Non-PV triggers, however, are also important, especially for late recurrence of $\mathrm{AF} .{ }^{39}$ Non-PV triggers have been reported in up to one-third of unselected patients with paroxysmal AF, with origin from various sites such as the posterior LA, the superior vena cava, the inferior vena cava, crista terminalis, fossa ovalis, coronary sinus, Eustachian ridge, ligament of Marshall, and adjacent to the AV valve annuli. ${ }^{39}$ These triggers, when reproducibly provocable and mappable, may allow successful ablation of paroxysmal AF refractory to prior catheter ablation procedures in the presence of isolated PVs. However, ensuring that the PVs remain isolated is critical for determining ultimate success, which can be achieved in the majority of patients with one or more procedures. Indeed, in a recent randomized trial, redo AF ablation was substantially more effective than antiarrhythmic drugs in reducing the progression and prevalence of $\mathrm{AF}$ after the failure of an initial ablation. ${ }^{83}$
It is important to note that late AF recurrence may also be due to ongoing electrical and structural remodeling of the atria as a result of comorbidities such as aging, heart failure, inflammation, diabetes, and obesity. ${ }^{39}$ Recent studies have shown that aggressive risk factor management such as sustained weight loss (and avoidance of weight fluctuation), reductions in blood pressure, and improved glycemic control and lipid profiles was associated with reduced frequency, duration, symptoms, and symptom severity in AF. ${ }^{84,85}$ This translated to improved single- and multiple-procedure drugfree AF-free survival compared with control patients. ${ }^{84,85}$ However, there is recognition that there may be a subset of patients with paroxysmal lone AF with evidence of abnormal atrial substrate which may not reverse even after successful catheter ablation, and may even progress. ${ }^{86}$

\section{Reasons for electrical reconnection between the PVs and the LA}

Putative reasons for resumption of PV-LA conduction are gaps within the ablation line ${ }^{87}$ and/or failure to produce transmural lesions. ${ }^{88}$ Gaps in lines allow resumption of PV-to-LA electrical activity allowing PV triggers to reinitiate AF and may also serve as triggers for other macroreentrant atrial arrhythmias. ${ }^{72,73,79,82,89}$ In a histopathologic study in patients undergoing MAZE for recurrent AF after initially successful catheter ablation for AF, Kowalski et al ${ }^{88}$ performed intraoperative assessment of PV-LA junction conduction during the procedure and took biopsies from the PV antrum at sites of endocardial scar. They found that PVs showing electrical reconnection after catheter-based RF ablation frequently exhibited either anatomic gaps or nontransmural lesions at sites of ablation. However nontransmural lesions in some PVs had evidence of persistent PV-LA block, suggesting the fact that lesion geometry may influence PV conduction. ${ }^{88}$ Indeed, gap geometry has a critical influence on conduction through discontinuities in RF lesions such that bifurcated (Y-shaped) or angled gaps (containing two right angles within the conduction path) were less likely to produce bidirectional conduction block but were more likely to produce a unidirectional or rate-dependent conduction block than straight gaps..$^{90}$

Despite an apparently successful lesion at a particular site, conduction recovery over that site may occur. At such a site, there may be an acute loss of electrical signals and electrical inexcitability as both reversible and irreversible cell injury has occurred. Reversible atrial injury may stem from incomplete lesion formation that results in temporary electrical uncoupling but not cell death. Ablation of atrial 
tissue alters its electrophysiological behavior; this process is dependent on tissue temperature and distance from the ablation site. ${ }^{91-93}$ Tissue heating can cause acute, transient conduction block. ${ }^{91,92}$ Furthermore, acute change in atrial electrophysiological properties (action potential changes) can be observed up to $3.5 \mathrm{~mm}$ away from the boundary of a lesion producing transient block.

Indeed, acute PVI may be achieved by a combination of reversible and irreversible circumferential tissue injury. ${ }^{94}$ A broad anterograde wavefront of edema on the leading edge of each lesion may be present that is capable of producing conduction block. This possibility may explain why PVI can often be achieved without complete PV encirclement. ${ }^{95}$ With time, tissue at the boundary of the lesion recovers normal conduction over the course of 1-4 weeks. ${ }^{93}$ This allows for gaps within an ablation line to initially exhibit conduction block, and thus remain undetected (ie, electrically silent) during the index procedure. With time, as tissue recovers, conduction occurs through gaps in the ablation lines. ${ }^{96}$

The size of the maximum permissible gap between each lesion varies as a function of tissue conductivity such that normal conductivity may produce conduction block despite a gap of up to $1.4 \mathrm{~mm}$, whereas with impaired tissue conductivity, a gap length as large as $4 \mathrm{~mm}$ can acutely produce conduction block. ${ }^{96}$ Gap geometry also influences conduction, with complex gap geometry through discontinuous ablation lines permitting unidirectional and/or ratedependent block. ${ }^{90}$

Gap detection during an index case is facilitated by a visual $\log$ of lesions on an electroanatomic mapping system and via residual electrical signals detected by a multipolar mapping catheter placed at the PV-LA junction. Fundamentally, this will miss electrically silent gaps that can appear as a result of the aforementioned mechanisms. Dormant conduction can be identified by use of intravenous adenosine, which hyperpolarizes atrial cell membranes, permitting transient conduction at sites with incomplete cell destruction. ${ }^{97}$ Whilst further ablation at these sites can improve AF-free survival, ${ }^{80,98}$ paradoxically it also identifies those patients with a greater likelihood of AF recurrence despite additional ablation, possibly reflecting global, incomplete transmural encirclement. ${ }^{99}$ The Adenosine Following Pulmonary Vein Isolation to Target Dormant Conduction Elimination (ADVICE) trial, which randomized patients with adenosine-induced dormant conduction to no further ablation versus additional adenosine-guided ablation until dormant conduction was abolished, showed that this "provoke-and-ablate" strategy improved AF ablation outcomes. ${ }^{100}$ High-resolution magnetic resonance imaging scanning and lesion thermography hold promise for gap detection and treatment but are not widely available. ${ }^{87,94,96,101} \mathrm{~A}$ unifying message from these studies is that acute electrical isolation does not reliably predict permanent electrical isolation.

Permanent conduction block across linear lesions requires transmural lesions. ${ }^{102}$ There is a limited number of reliable, easily reproducible methods for assessing intraprocedural lesion completeness. Loss of bipolar capture post-ablation predicts the formation of uniform transmural lesions, especially if catheter-tissue contact can be optimized, ${ }^{103}$ and is superior to electrogram-based detection of gaps in ablation lines. ${ }^{104}$ Indeed, loss of electrical excitability along a circumferential PVI line reduces acute PV conduction recovery ${ }^{105}$ and markedly enhances single-procedure success of AF ablation compared with bidirectional PV-LA conduction block alone. ${ }^{106}$ Magnetic resonance imaging detection of lesion transmurality is promising but not universally available. ${ }^{87,94,96}$

\section{Importance of catheter-tissue contact force in creating durable PV-LA conduction block}

One of the key factors that influences transmural lesion formation is catheter-tissue contact force $(\mathrm{CF})$. Use of $\mathrm{CF}$ technology can improve lesion efficacy, reduce PV conduction recovery, ${ }^{107,108}$ and improve single-procedure efficacy. ${ }^{109}$ Increasing $\mathrm{CF}$ has been shown to correlate with increasing lesion size, volume, and depth. ${ }^{110-117}$ Traditionally, contact has been inferred by using surrogate markers such as tactile feedback, catheter motion on fluoroscopy or nonfluoroscopic mapping systems, ${ }^{117,118}$ baseline electrogram amplitude and abatement with ablation and impedance decrease. ${ }^{117,119-122}$ These surrogate markers have recently been shown to be of limited predictive value for actual contact. ${ }^{123-128}$ During catheter ablation of AF, low CF $(<15$ grams [g]) is implicated in longer duration of ablation to achieve acute PV isolation, ${ }^{107,123,129}$ higher likelihood of acute PV conduction recovery, ${ }^{107,129,130}$ and late recurrence of $\mathrm{AF} .{ }^{131,132}$ All patients undergoing ablation with an average $\mathrm{CF}<10 \mathrm{~g}$ experienced AF recurrence at 12 months, whereas $80 \%$ of patients with an average $\mathrm{CF}>20 \mathrm{~g}$ during the procedure were free of $\mathrm{AF}$ at 12 months in one study. ${ }^{131}$ Furthermore, $75 \%$ of the patients treated with $<500$ grams $\times$ seconds $\left(\mathrm{g}^{*} \mathrm{~s}\right)$ experienced recurrent $\mathrm{AF}$, whereas only $31 \%$ of the patients treated with $>1,000 \mathrm{~g} *^{\mathrm{s}}$ had recurrences at 12 months. ${ }^{131}$ The importance of quality of $\mathrm{CF}$, not quantity alone, was emphasized in the prospective, multicenter SMART-AF trial that evaluated 
the safety and effectiveness of an irrigated CF catheter in patients with paroxysmal AF. This study demonstrated that an absolute higher CF per se did not correlate with improved AF-free survival. If the investigator worked in their preselected working range of $\mathrm{CF} \geq 80 \%$ of the time, this translated to a four-fold increase in freedom from recurrent AF. It is important to note, however, that the use of this technology did not reduce the incidence of complications related to the force applied to the catheter tip. ${ }^{133}$

The optimal $\mathrm{CF}$ required to create transmural lesions safely is also not clear. Whilst the aforementioned studies showed superior outcomes with $>20 \mathrm{~g}$ of $\mathrm{CF}$, other studies using EGM criteria for assessing lesion transmurality showed that an average $\mathrm{CF}>16 \mathrm{~g}$ or force-time integral (FTI) $>404 \mathrm{~g}^{*}$ s had excellent sensitivity and specificity (>80\%) for predicting a transmural lesion based on EGM criteria. ${ }^{134,135}$ The EFFICAS I study examined 46 patients undergoing PV isolation for paroxysmal AF by operators blinded to CF. ${ }^{132}$ Of the 46 patients, 40 underwent a repeated interventional study at 3 months to assess gap location and its relationship to $\mathrm{CF}$ recorded at the index procedure. PV segments with a FTI $<400 \mathrm{~g}^{*}$ s had a $79 \%$ likelihood of remaining isolated, whereas those with a minimum FTI $>400 \mathrm{~g} * \mathrm{~s}$ had a $95 \%$ chance of remaining isolated. ${ }^{132}$ Reconnection correlated strongly with minimum CF and minimum FTI at the site of gap.

Although monitoring of catheter-tissue CF appears to improve lesion efficacy, rigorous impedance monitoring in combination with catheter stability also results in better lesion efficacy. Anter et al ${ }^{136}$ showed that an automated RF ablation combining preset criteria of catheter stability ( $\leq 2 \mathrm{~mm}$ catheter motion for $>15$ seconds) in addition to an impedance decrease of $\geq 5 \%$ resulted in improved outcomes. This study showed a lower incidence of "gaps" upon completion of the anatomic ring, higher incidence of effective lesions, lower frequency of acute conduction recovery, and a trend toward higher arrhythmia-free survival at 6 months with these preset criteria. The comparator group were patients who had ablation based on the operator's own definition of catheter stability and lesion efficacy based on conventional modalities such as fluoroscopy, intracardiac echocardiography, and review of changes in tissue impedance and local electrogram. ${ }^{136}$

Reichlin et al also showed a very high incidence of AF-free survival when point-by-point wide antral PVI was performed, with each lesion achieving at least a 5-ohm fall in impedance. ${ }^{137}$ Hence, conscious efforts to improve lesion transmurality by meticulously achieving preset goals of biophysical parameters for every lesion is likely to provide the greatest improvement in single-procedure efficacy. ${ }^{106,108,137}$

\section{Complications of catheter ablation for AF}

Complications of catheter ablation are also covered in detail elsewhere ${ }^{39,138-140}$ and are summarized in Table $1 .{ }^{138} \mathrm{~A}$ recent meta-analysis of all AF ablation studies showed that the complication rate is $2.9 \%$ (95\% confidence interval 2.6-3.2). ${ }^{138}$ Rates of serious complications, however, are low in experienced hands in patients with paroxysmal AF with no structural heart disease. ${ }^{141}$ Common serious complications are usually related to vascular access or cardiac perforation related to catheter manipulation or transseptal puncture causing tamponade. Less frequently, serious collateral injury to structures contiguous with the LA, such as the phrenic nerve or esophagus, is observed. Procedural modifications have reduced the incidence of thromboembolism (eg, stroke) related to subtherapeutic anticoagulation in the peri- and intraprocedural period, and PV stenosis related to ablation within the PV ostium.

Table I Complications of catheter ablation for AF

\begin{tabular}{|c|c|c|c|}
\hline & $\begin{array}{l}\text { No of } \\
\text { studies }\end{array}$ & $\begin{array}{l}\% \text { pooled } \\
\text { complication rate }\end{array}$ & $\begin{array}{l}I^{2} \\
\text { statistic }\end{array}$ \\
\hline Acute complication rate & 183 & $2.9(2.6-3.22)$ & 83.8 \\
\hline \multicolumn{4}{|l|}{ Type of complication } \\
\hline Death & 58 & $0.06(0.03-0.09)$ & 0 \\
\hline Atrioesophageal fistula & 67 & $0.08(0.05-0.11)$ & 0 \\
\hline Pulmonary vein stenosis & 118 & $0.5(0.34-0.6)$ & 79.6 \\
\hline Vascular complications & 117 & $1.4(1.02-1.79)$ & 94.1 \\
\hline Arteriovenous fistula & 45 & $0.4(0.28-0.55)$ & 45.5 \\
\hline $\begin{array}{l}\text { Femoral } \\
\text { pseudoaneurysm }\end{array}$ & 49 & $0.5(0.34-0.6)$ & 41.2 \\
\hline Stroke/TIA & 155 & $0.6(0.5-0.67)$ & 46.8 \\
\hline Stroke & $\mathrm{III}$ & $0.4(0.3-0.44)$ & 34.3 \\
\hline TIA & 94 & $0.4(0.28-0.47)$ & 37.9 \\
\hline Tamponade & $|3|$ & I (0.83-I.I4) & 68.5 \\
\hline Pericardial effusion & 67 & $0.7(0.56-0.88)$ & 55 \\
\hline Phrenic nerve injury & 48 & $0.4(0.22-0.54)$ & 70.2 \\
\hline Diaphragmatic paralysis & 21 & $0.3(0.15-0.43)$ & 0 \\
\hline DVT/PE & 33 & $0.15(0.09-0.21)$ & 0 \\
\hline Pneumothorax & 22 & $0.2(0.08-0.29)$ & 0 \\
\hline Hemothorax & 25 & $0.2(0.1-0.28)$ & 0 \\
\hline $\begin{array}{l}\text { Sepsis, abscesses, or } \\
\text { endocarditis }\end{array}$ & 20 & $0.1(0.06-0.24)$ & 0 \\
\hline Valve damage & 26 & $0.2(0.08-0.25)$ & 0 \\
\hline
\end{tabular}

Notes: Copyright (C) 2013. Reprinted from Wolters Kluwer Health, Inc. Gupta A, Perera T, Ganesan A, et al. Complications of catheter ablation of atrial fibrillation: a systematic review. Circ Arrhythm Electrophysiol. 2013;6(6):1082-1088. ${ }^{138}$ Promotional and commercial use of the material in print, digital or mobile device format is prohibited without the permission from the publisher Wolters Kluwer Health. Please contact healthpermissions@wolterskluwer.com for further information. Abbreviations: DVT, deep-vein thrombosis; PE, pulmonary embolus; TIA, transient ischemic attack; AF, arteriovenous fistula. 


\section{Conclusion}

This review summarizes the contribution of the PVs to AF maintenance, pertinent aspects of $\mathrm{PV}$ electrophysiology that contribute to the initiation of AF, and the role of PV isolation as the cornerstone of modern AF ablation strategies. Important differences in the anatomic, autonomic, and electrophysiologic properties of the PVs play a key role in the initiation and maintenance of AF, although much further work is needed to elucidate specific mechanisms by which AF initiates within the PVs. Despite an exponential increase in AF ablation procedures worldwide, efficacy remains suboptimal, likely due to inability to create durable transmural lesions with subsequent recovery of electrical conduction. Important challenges remain to refine catheter ablation to make it a procedure that provides long-term control of AF.

\section{Disclosure}

Dr Kumar is a recipient of the Neil Hamilton Fairley Overseas Research scholarship, co-funded by the National Health and Medical Research Council and the National Heart Foundation of Australia; and the Bushell Travelling Fellowship, funded by the Royal Australasian College of Physicians. Dr Michaud receives consulting fees/honoraria from Boston Scientific Corporation, Medtronic, Inc., and St Jude Medical, and research funding from Boston Scientific Corporation and Biosense Webster, Inc.

\section{References}

1. Go AS, Hylek EM, Phillips KA, et al. Prevalence of diagnosed atrial fibrillation in adults: national implications for rhythm management and stroke prevention: the AnTicoagulation and Risk Factors in Atrial Fibrillation (ATRIA) Study. JAMA. 2001;285(18):2370-2375.

2. Haïssaguerre M, Jaïs $P$, Shah DC, et al. Spontaneous initiation of atrial fibrillation by ectopic beats originating in the pulmonary veins. $N$ Engl J Med. 1998;339(10):659-666.

3. Schotten U, Verheule S, Kirchhof P, Goette A. Pathophysiological mechanisms of atrial fibrillation: a translational appraisal. Physiol Rev. 2011;91(1):265-325.

4. Narayan SM, Jalife J. Rebuttal from Sanjiv M. Narayan and José Jalife. J Physiol. 2014;592(Pt 15):3171.

5. Narayan SM, Jalife J. CrossTalk proposal: Rotors have been demonstrated to drive human atrial fibrillation. $J$ Physiol. 2014;592(Pt 15):3163-3166.

6. Allessie M, de Groot N. CrossTalk opposing view: Rotors have not been demonstrated to be the drivers of atrial fibrillation. $J$ Physiol. 2014;592(Pt 15):3167-3170.

7. Lalani GG, Trikha R, Krummen DE, Narayan SM. Rotors and focal sources for human atrial fibrillation: mechanistic paradigm with direct clinical relevance. Circ J. 2014;78(10):2357-2366.

8. de Groot NM, Houben RP, Smeets JL, et al. Electropathological substrate of longstanding persistent atrial fibrillation in patients with structural heart disease: epicardial breakthrough. Circulation. 2010;122(17):1674-1682.

9. Andrikopoulos G, Tzeis S, Vardas PE. Invasive therapy for atrial fibrillation: recent developments in ablation, navigation and mapping technology. Heart. 2011;97(3):237-243.
10. Benjamin EJ, Levy D, Vaziri SM, D’Agostino RB, Belanger AJ, Wolf PA. Independent risk factors for atrial fibrillation in a population-based cohort. The Framingham Heart Study. JAMA. 1994;271(11):840-844.

11. Lloyd-Jones DM, Wang TJ, Leip EP, et al. Lifetime risk for development of atrial fibrillation: the Framingham Heart Study. Circulation. 2004;110(9):1042-1046.

12. Benjamin EJ, Chen PS, Bild DE, et al. Prevention of atrial fibrillation: report from a national heart, lung, and blood institute workshop. Circulation. 2009;119(4):606-618.

13. Le Heuzey JY, Paziaud O, Piot O, et al. Cost of care distribution in atrial fibrillation patients: the COCAF study. Am Heart J. 2004;147(1): 121-126.

14. Reynolds MR, Essebag V, Zimetbaum P, Cohen DJ. Healthcare resource utilization and costs associated with recurrent episodes of atrial fibrillation: the FRACTAL registry. $J$ Cardiovasc Electrophysiol. 2007;18(6):628-633.

15. European Heart Rhythm Association; European Association for CardioThoracic Surgery, Camm AJ, Kirchhof P, et al. Guidelines for the management of atrial fibrillation: the Task Force for the Management of Atrial Fibrillation of the European Society of Cardiology (ESC). Eur Heart J. 2010;31(19):2369-2429.

16. Narayan SM, Krummen DE, Shivkumar K, Clopton P, Rappel WJ, Miller JM. Treatment of atrial fibrillation by the ablation of localized sources: CONFIRM (Conventional Ablation for Atrial Fibrillation With or Without Focal Impulse and Rotor Modulation) trial. J Am Coll Cardiol. 2012;60(7):628-636.

17. Nattel S. Paroxysmal atrial fibrillation and pulmonary veins: relationships between clinical forms and automatic versus re-entrant mechanisms. Can J Cardiol. 2013;29(10):1147-1149.

18. Gillis AM, Krahn AD, Skanes AC, Nattel S. Management of atrial fibrillation in the year 2033: new concepts, tools, and applications leading to personalized medicine. Can J Cardiol. 2013;29(10):1141-1146.

19. Nathan H, Eliakim M. The junction between the left atrium and the pulmonary veins. An anatomic study of human hearts. Circulation. 1966;34(3):412-422.

20. Arora R, Verheule S, Scott L, et al. Arrhythmogenic substrate of the pulmonary veins assessed by high-resolution optical mapping. Circulation. 2003;107(13):1816-1821

21. Hocini M, Ho SY, Kawara T, et al. Electrical conduction in canine pulmonary veins: electrophysiological and anatomic correlation. Circulation. 2002;105(20):2442-2448.

22. Ehrlich JR, Cha TJ, Zhang L, et al. Cellular electrophysiology of canine pulmonary vein cardiomyocytes: action potential and ionic current properties. J Physiol. 2003;551(Pt 3):801-813.

23. Chen YJ, Chen SA. Electrophysiology of pulmonary veins. J Cardiovasc Electrophysiol. 2006;17(2):220-224.

24. Atienza F, Almendral J, Moreno J, et al. Activation of inward rectifier potassium channels accelerates atrial fibrillation in humans: evidence for a reentrant mechanism. Circulation. 2006;114(23):2434-2442.

25. Sanders P, Berenfeld O, Hocini M, et al. Spectral analysis identifies sites of high-frequency activity maintaining atrial fibrillation in humans. Circulation. 2005;112(6):789-797.

26. Ho SY, Cabrera JA, Tran VH, Farré J, Anderson RH, Sánchez-Quintana D. Architecture of the pulmonary veins: relevance to radiofrequency ablation. Heart. 2001;86(3):265-270.

27. Ho SY, Sanchez-Quintana D, Cabrera JA, Anderson RH. Anatomy of the left atrium: implications for radiofrequency ablation of atrial fibrillation. J Cardiovasc Electrophysiol. 1999;10(11):1525-1533.

28. Saito T, Waki K, Becker AE. Left atrial myocardial extension onto pulmonary veins in humans: anatomic observations relevant for atrial arrhythmias. J Cardiovasc Electrophysiol. 2000;11(8):888-894.

29. Schauerte P, Scherlag BJ, Patterson E, et al. Focal atrial fibrillation: experimental evidence for a pathophysiologic role of the autonomic nervous system. $J$ Cardiovasc Electrophysiol. 2001;12(5): 592-599.

30. Vaitkevicius R, Saburkina I, Rysevaite K, et al. Nerve supply of the human pulmonary veins: an anatomical study. Heart Rhythm. 2009;6(2):221-228. 
31. Jaïs P, Hocini M, Macle L, et al. Distinctive electrophysiological properties of pulmonary veins in patients with atrial fibrillation. Circulation. 2002;106(19):2479-2485.

32. Rostock T, Steven D, Lutomsky B, et al. Atrial fibrillation begets atrial fibrillation in the pulmonary veins on the impact of atrial fibrillation on the electrophysiological properties of the pulmonary veins in humans. J Am Coll Cardiol. 2008;51(22):2153-2160.

33. Teh AW, Kistler PM, Lee G, et al. Electroanatomic properties of the pulmonary veins: slowed conduction, low voltage and altered refractoriness in AF patients. J Cardiovasc Electrophysiol. 2011;22(10):1083-1091.

34. Miragoli M, Gaudesius G, Rohr S. Electrotonic modulation of cardiac impulse conduction by myofibroblasts. Circ Res. 2006;98(6):801-810.

35. Lee G, Spence S, Teh A, et al. High-density epicardial mapping of the pulmonary vein-left atrial junction in humans: insights into mechanisms of pulmonary vein arrhythmogenesis. Heart Rhythm. 2012;9(2):258-264.

36. Walters TE, Lee G, Spence $S$, et al. Acute atrial stretch results in conduction slowing and complex signals at the pulmonary vein to left atrial junction: insights into the mechanism of pulmonary vein arrhythmogenesis. Circ Arrhythm Electrophysiol. 2014;7(6):1189-1197.

37. Stiles MK, John B, Wong CX, et al. Paroxysmal lone atrial fibrillation is associated with an abnormal atrial substrate: characterizing the "second factor". J Am Coll Cardiol. 2009;53(14):1182-1191.

38. Chou CC, Chen PS. New concepts in atrial fibrillation: neural mechanisms and calcium dynamics. Cardiol Clin. 2009;27(1):35-43, viii.

39. Calkins H, Kuck KH, Cappato R, et al; Heart Rhythm Society Task Force on Catheter and Surgical Ablation of Atrial Fibrillation. 2012 HRS/EHRA/ECAS expert consensus statement on catheter and surgical ablation of atrial fibrillation: recommendations for patient selection, procedural techniques, patient management and follow-up, definitions, endpoints, and research trial design: a report of the Heart Rhythm Society (HRS) Task Force on Catheter and Surgical Ablation of Atrial Fibrillation. Developed in partnership with the European Heart Rhythm Association (EHRA), a registered branch of the European Society of Cardiology (ESC) and the European Cardiac Arrhythmia Society (ECAS); and in collaboration with the American College of Cardiology (ACC), American Heart Association (AHA), the Asia Pacific Heart Rhythm Society (APHRS), and the Society of Thoracic Surgeons (STS) Endorsed by the governing bodies of the American College of Cardiology Foundation, the American Heart Association, the European Cardiac Arrhythmia Society, the European Heart Rhythm Association, the Society of Thoracic Surgeons, the Asia Pacific Heart Rhythm Society, and the Heart Rhythm Society. Heart Rhythm. 2012;9(4):632-696.e621.

40. de Vos CB, Nieuwlaat R, Crijns HJ, et al. Autonomic trigger patterns and anti-arrhythmic treatment of paroxysmal atrial fibrillation: data from the Euro Heart Survey. Eur Heart J. 2008;29(5):632-639.

41. Fioranelli M, Piccoli M, Mileto GM, et al. Analysis of heart rate variability five minutes before the onset of paroxysmal atrial fibrillation. Pacing Clin Electrophysiol. 1999;22(5):743-749.

42. Kneller J, Zou R, Vigmond EJ, Wang Z, Leon LJ, Nattel S. Cholinergic atrial fibrillation in a computer model of a two-dimensional sheet of canine atrial cells with realistic ionic properties. Circ Res. 2002;90(9): E73-E87.

43. Sarmast F, Kolli A, Zaitsev A, et al. Cholinergic atrial fibrillation: $\mathrm{I}(\mathrm{K}, \mathrm{ACh})$ gradients determine unequal left/right atrial frequencies and rotor dynamics. Cardiovasc Res. 2003;59(4):863-873.

44. Voigt N, Trausch A, Knaut M, et al. Left-to-right atrial inward rectifier potassium current gradients in patients with paroxysmal versus chronic atrial fibrillation. Circ Arrhythm Electrophysiol. 2010;3(5): 472-480.

45. Dobrev D, Nattel S. New insights into the molecular basis of atrial fibrillation: mechanistic and therapeutic implications. Cardiovasc Res. 2011;89(4):689-691.

46. Gould PA, Yii M, McLean C, et al. Evidence for increased atrial sympathetic innervation in persistent human atrial fibrillation. Pacing Clin Electrophysiol. 2006;29(8):821-829.

47. Tan AY, Zhou S, Ogawa M, et al. Neural mechanisms of paroxysmal atrial fibrillation and paroxysmal atrial tachycardia in ambulatory canines. Circulation. 2008;118(9):916-925.
48. Yu L, Scherlag BJ, Sha Y, et al. Interactions between atrial electrical remodeling and autonomic remodeling: how to break the vicious cycle. Heart Rhythm. 2012;9(5):804-809.

49. Pokushalov E, Romanov A, Artyomenko S, Turov A, Shirokova N, Katritsis DG. Left atrial ablation at the anatomic areas of ganglionated plexi for paroxysmal atrial fibrillation. Pacing Clin Electrophysiol. 2010;33(10):1231-1238.

50. Lemery R, Birnie D, Tang AS, Green M, Gollob M. Feasibility study of endocardial mapping of ganglionated plexuses during catheter ablation of atrial fibrillation. Heart Rhythm. 2006;3(4):387-396.

51. Katritsis DG, Pokushalov E, Romanov A, et al. Autonomic denervation added to pulmonary vein isolation for paroxysmal atrial fibrillation: a randomized clinical trial. J Am Coll Cardiol. 2013;62(24): 2318-2325.

52. Kumar S, Walters TE, Halloran K, et al. Ten-year trends in the use of catheter ablation for treatment of atrial fibrillation vs. the use of coronary intervention for the treatment of ischaemic heart disease in Australia. Europace. 2013;15(12):1702-1709.

53. Arentz T, Weber R, Bürkle G, et al. Small or large isolation areas around the pulmonary veins for the treatment of atrial fibrillation? Results from a prospective randomized study. Circulation. 2007;115(24):3057-3063.

54. Proietti R, Santangeli P, Di Biase L, et al. Comparative effectiveness of wide antral versus ostial pulmonary vein isolation: a systematic review and meta-analysis. Circ Arrhythm Electrophysiol. 2014;7(1): 39-45.

55. Kiuchi K, Kircher S, Watanabe N, et al. Quantitative analysis of isolation area and rhythm outcome in patients with paroxysmal atrial fibrillation after circumferential pulmonary vein antrum isolation using the pace-and-ablate technique. Circ Arrhythm Electrophysiol. 2012;5(4):667-675.

56. Wynn GJ, Das M, Bonnett LJ, Panikker S, Wong T, Gupta D. Efficacy of catheter ablation for persistent atrial fibrillation: a systematic review and meta-analysis of evidence from randomized and nonrandomized controlled trials. Circ Arrhythm Electrophysiol. 2014;7(5): 841-852.

57. Pappone C, Vicedomini G, Augello G, et al. Radiofrequency catheter ablation and antiarrhythmic drug therapy: a prospective, randomized, 4-year follow-up trial: the APAF study. Circ Arrhythm Electrophysiol. 2011;4(6):808-814.

58. Jaïs P, Cauchemez B, Macle L, et al. Catheter ablation versus antiarrhythmic drugs for atrial fibrillation: the A4 study. Circulation. 2008;118(24):2498-2505.

59. Wazni OM, Marrouche NF, Martin DO, et al. Radiofrequency ablation vs antiarrhythmic drugs as first-line treatment of symptomatic atrial fibrillation: a randomized trial. JAMA. 2005;293(21): 2634-2640.

60. Wilber DJ, Pappone C, Neuzil P, et al; ThermoCool AF Trial Investigators. Comparison of antiarrhythmic drug therapy and radiofrequency catheter ablation in patients with paroxysmal atrial fibrillation: a randomized controlled trial. JAMA. 2010;303(4):333-340.

61. Noheria A, Kumar A, Wylie JV Jr, Josephson ME. Catheter ablation vs antiarrhythmic drug therapy for atrial fibrillation: a systematic review. Arch Intern Med. 2008;168(6):581-586.

62. Piccini JP, Lopes RD, Kong MH, Hasselblad V, Jackson K, Al-Khatib SM. Pulmonary vein isolation for the maintenance of sinus rhythm in patients with atrial fibrillation: a meta-analysis of randomized, controlled trials. Circ Arrhythm Electrophysiol. 2009;2(6):626-633.

63. Calkins H, Reynolds MR, Spector P, et al. Treatment of atrial fibrillation with antiarrhythmic drugs or radiofrequency ablation: two systematic literature reviews and meta-analyses. Circ Arrhythm Electrophysiol. 2009;2(4):349-361.

64. Ouyang F, Tilz R, Chun J, et al. Long-term results of catheter ablation in paroxysmal atrial fibrillation: lessons from a 5-year follow-up. Circulation. 2010;122(23):2368-2377.

65. Weerasooriya R, Khairy P, Litalien J, et al. Catheter ablation for atrial fibrillation: are results maintained at 5 years of follow-up? J Am Coll Cardiol. 2011;57(2):160-166. 
66. Sawhney N, Anousheh R, Chen WC, Narayan S, Feld GK. Five-year outcomes after segmental pulmonary vein isolation for paroxysmal atrial fibrillation. Am J Cardiol. 2009;104(3):366-372.

67. Medi C, Sparks PB, Morton JB, et al. Pulmonary vein antral isolation for paroxysmal atrial fibrillation: results from long-term follow-up. J Cardiovasc Electrophysiol. 2011;22(2):137-141.

68. Tzou WS, Marchlinski FE, Zado ES, et al. Long-term outcome after successful catheter ablation of atrial fibrillation. Circ Arrhythm Electrophysiol. 2010;3(3):237-242.

69. Scaglione M, Gallo C, Battaglia A, et al. Long-term progression from paroxysmal to permanent atrial fibrillation following transcatheter ablation in a large single-center experience. Heart Rhythm. 2014;11(5):777-782.

70. Cosedis Nielsen J, Johannessen A, Raatikainen P, et al. Radiofrequency ablation as initial therapy in paroxysmal atrial fibrillation. $N$ Engl $J$ Med. 2012;367(17):1587-1595.

71. Khan AR, Khan S, Sheikh MA, Khuder S, Grubb B, Moukarbel GV. Catheter ablation and antiarrhythmic drug therapy as first- or second-line therapy in the management of atrial fibrillation: systematic review and meta-analysis. Circ Arrhythm Electrophysiol. 2014;7(5): 853-860.

72. Verma A, Kilicaslan F, Pisano E, et al. Response of atrial fibrillation to pulmonary vein antrum isolation is directly related to resumption and delay of pulmonary vein conduction. Circulation. 2005;112(5):627-635.

73. Ouyang F, Antz M, Ernst S, et al. Recovered pulmonary vein conduction as a dominant factor for recurrent atrial tachyarrhythmias after complete circular isolation of the pulmonary veins: lessons from double Lasso technique. Circulation. 2005;111(2):127-135.

74. Lee G, Wu H, Kalman JM, et al. Atrial fibrillation following lung transplantation: double but not single lung transplant is associated with long-term freedom from paroxysmal atrial fibrillation. Eur Heart $J$. 2010;31(22):2774-2782.

75. Dixit S, Gerstenfeld EP, Ratcliffe SJ, et al. Single procedure efficacy of isolating all versus arrhythmogenic pulmonary veins on long-term control of atrial fibrillation: a prospective randomized study. Heart Rhythm. 2008;5(2):174-181.

76. Atienza F, Almendral J, Ormaetxe JM, et al; RADAR-AF Investigators. Comparison of radiofrequency catheter ablation of drivers and circumferential pulmonary vein isolation in atrial fibrillation: a noninferiority randomized multicenter RADAR-AF trial. J Am Coll Cardiol. 2014;64(23):2455-2467.

77. Jiang RH, Po SS, Tung R, et al. Incidence of pulmonary vein conduction recovery in patients without clinical recurrence after ablation of paroxysmal atrial fibrillation: mechanistic implications. Heart Rhythm. 2014;11(6):969-976.

78. Ganesan AN, Shipp NJ, Brooks AG, et al. Long-term outcomes of catheter ablation of atrial fibrillation: a systematic review and metaanalysis. J Am Heart Assoc. 2013;2(2):e004549.

79. Cheema A, Dong J, Dalal D, et al. Incidence and time course of early recovery of pulmonary vein conduction after catheter ablation of atrial fibrillation. J Cardiovasc Electrophysiol. 2007;18(4):387-391.

80. Wang XH, Liu X, Sun YM, et al. Early identification and treatment of PV re-connections: role of observation time and impact on clinical results of atrial fibrillation ablation. Europace. 2007;9(7):481-486.

81. Kumar S, Michaud GF. Unipolar electrogram morphology to assess lesion formation during catheter ablation of atrial fibrillation: successful translation into clinical practice. Circ Arrhythm Electrophysiol. 2013;6(6):1050-1052.

82. Nanthakumar K, Plumb VJ, Epstein AE, Veenhuyzen GD, Link D, Kay GN. Resumption of electrical conduction in previously isolated pulmonary veins: rationale for a different strategy? Circulation. 2004;109(10):1226-1229.

83. Pokushalov E, Romanov A, De Melis M, et al. Progression of atrial fibrillation after a failed initial ablation procedure in patients with paroxysmal atrial fibrillation: a randomized comparison of drug therapy versus reablation. Circ Arrhythm Electrophysiol. 2013;6(4):754-760.
84. Pathak RK, Middeldorp ME, Lau DH, et al. Aggressive risk factor reduction study for atrial fibrillation and implications for the outcome of ablation: the ARREST-AF cohort study. J Am Coll Cardiol. 2014;64(21):2222-2231.

85. Pathak RK, Middeldorp ME, Meredith M, et al. Long-Term Effect of Goal-Directed Weight Management in an Atrial Fibrillation Cohort: A Long-Term Follow-Up Study (LEGACY). J Am Coll Cardiol. 2015

86. Teh AW, Kistler PM, Lee G, et al. Long-term effects of catheter ablation for lone atrial fibrillation: progressive atrial electroanatomic substrate remodeling despite successful ablation. Heart Rhythm. 2012;9(4):473-480.

87. Ranjan R, Kholmovski EG, Blauer J, et al. Identification and acute targeting of gaps in atrial ablation lesion sets using a real-time magnetic resonance imaging system. Circ Arrhythm Electrophysiol. 2012;5(6):1130-1135.

88. Kowalski M, Grimes MM, Perez FJ, et al. Histopathologic characterization of chronic radiofrequency ablation lesions for pulmonary vein isolation. J Am Coll Cardiol. 2012;59(10):930-938.

89. Cappato R, Negroni S, Pecora D, et al. Prospective assessment of late conduction recurrence across radiofrequency lesions producing electrical disconnection at the pulmonary vein ostium in patients with atrial fibrillation. Circulation. 2003;108(13): 1599-1604.

90. Pérez FJ, Wood MA, Schubert CM. Effects of gap geometry on conduction through discontinuous radiofrequency lesions. Circulation. 2006;113(14):1723-1729.

91. Nath S, Haines DE, Kron IL, DiMarco JP. The long-term outcome of visually directed subendocardial resection in patients without inducible or mappable ventricular tachycardia at the time of surgery. J Cardiovasc Electrophysiol. 1994;5(5):399-407.

92. Nath S, Redick JA, Whayne JG, Haines DE. Ultrastructural observations in the myocardium beyond the region of acute coagulation necrosis following radiofrequency catheter ablation. $J$ Cardiovasc Electrophysiol. 1994;5(10):838-845.

93. Wood MA, Fuller IA. Acute and chronic electrophysiologic changes surrounding radiofrequency lesions. J Cardiovasc Electrophysiol. 2002;13(1):56-61.

94. Arujuna A, Karim R, Caulfield D, et al. Acute pulmonary vein isolation is achieved by a combination of reversible and irreversible atrial injury after catheter ablation: evidence from magnetic resonance imaging. Circ Arrhythm Electrophysiol. 2012;5(4):691-700.

95. Miller MA, d'Avila A, Dukkipati SR, et al. Acute electrical isolation is a necessary but insufficient endpoint for achieving durable PV isolation: the importance of closing the visual gap. Europace. 2012;14(5):653-660.

96. Ranjan R, Kato R, Zviman MM, et al. Gaps in the ablation line as a potential cause of recovery from electrical isolation and their visualization using MRI. Circ Arrhythm Electrophysiol. 2011;4(3):279-286.

97. Datino T, Macle L, Qi XY, et al. Mechanisms by which adenosine restores conduction in dormant canine pulmonary veins. Circulation. 2010;121(8):963-972.

98. Yamane T, Matsuo S, Date T, et al. Repeated provocation of time- and ATP-induced early pulmonary vein reconnections after pulmonary vein isolation: eliminating paroxysmal atrial fibrillation in a single procedure. Circ Arrhythm Electrophysiol. 2011;4(5): 601-608.

99. McLellan AJ, Kumar S, Smith C, Morton JB, Kalman JM, Kistler PM. The role of adenosine following pulmonary vein isolation in patients undergoing catheter ablation for atrial fibrillation: a systematic review. J Cardiovasc Electrophysiol. 2013;24(7):742-751.

100. Macle L, Khairy P, Verma A, et al; ADVICE Study Investigators. Adenosine following pulmonary vein isolation to target dormant conduction elimination (ADVICE): methods and rationale. Can $J$ Cardiol. 2012;28(2):184-190. 
101. Kolandaivelu A, Zviman MM, Castro V, Lardo AC, Berger RD, Halperin HR. Noninvasive assessment of tissue heating during cardiac radiofrequency ablation using MRI thermography. Circ Arrhythm Electrophysiol. 2010;3(5):521-529.

102. Melby SJ, Lee AM, Zierer A, et al. Atrial fibrillation propagates through gaps in ablation lines: implications for ablative treatment of atrial fibrillation. Heart Rhythm. 2008;5(9):1296-1301.

103. Kosmidou I, Houde-Walter H, Foley L, Michaud G. Loss of pace capture after radiofrequency application predicts the formation of uniform transmural lesions. Europace. 2013;15(4):601-606.

104. Steven D, Reddy VY, Inada K, et al. Loss of pace capture on the ablation line: a new marker for complete radiofrequency lesions to achieve pulmonary vein isolation. Heart Rhythm. 2010;7(3):323-330.

105. Andrade JG, Pollak SJ, Monir G, et al. Pulmonary vein isolation using a pace-capture-guided versus an adenosine-guided approach: effect on dormant conduction and long-term freedom from recurrent atrial fibrillation - a prospective study. Circ Arrhythm Electrophysiol 2013.

106. Steven D, Sultan A, Reddy V, et al. Benefit of pulmonary vein isolation guided by loss of pace capture on the ablation line: results from a prospective 2-center randomized trial. J Am Coll Cardiol. 2013;62(1):44-50.

107. Kumar S, Morton JB, Lee J, et al. Prospective characterization of catheter-tissue contact force at different anatomic sites during antral pulmonary vein isolation. Circ Arrhythm Electrophysiol. 2012;5(6):1124-1129.

108. Kumar S, Chan M, Lee J, et al. Catheter-tissue contact force determines atrial electrogram characteristics before and lesion efficacy after antral pulmonary vein isolation in humans. $J$ Cardiovasc Electrophysiol. 2013;25(2):122-129.

109. Marijon E, Fazaa M, Narayanan K, et al. Real-time contact force sensing for pulmonary vein isolation in the setting of paroxysmal atrial fibrillation: procedural and 1-year results. J Cardiovasc Electrophysiol. 2014;25(2):130-137.

110. Yokoyama K, Nakagawa H, Shah DC, et al. Novel contact force sensor incorporated in irrigated radiofrequency ablation catheter predicts lesion size and incidence of steam pop and thrombus. Circ Arrhythm Electrophysiol. 2008;1(5):354-362.

111. Shah DC, Lambert H, Nakagawa H, Langenkamp A, Aeby N, Leo G. Area under the real-time contact force curve (force-time integral) predicts radiofrequency lesion size in an in vitro contractile model. J Cardiovasc Electrophysiol. 2010;21(9):1038-1043.

112. Avitall B, Mughal K, Hare J, Helms R, Krum D. The effects of electrode-tissue contact on radiofrequency lesion generation. Pacing Clin Electrophysiol. 1997;20(12 Pt 1):2899-2910.

113. Stagegaard N, Petersen HH, Chen X, Svendsen JH. Indication of the radiofrequency induced lesion size by pre-ablation measurements. Europace. 2005;7(6):525-534.

114. Weiss C, Antz M, Eick O, Eshagzaiy K, Meinertz T, Willems S. Radiofrequency catheter ablation using cooled electrodes: impact of irrigation flow rate and catheter contact pressure on lesion dimensions. Pacing Clin Electrophysiol. 2002;25(4 Pt 1):463-469.

115. Haines DE. Determinants of lesion size during radiofrequency catheter ablation: the role of electrode-tissue contact pressure and duration of energy delivery. J Cardiovasc Electrophysiol. 1991;2(6):509-515.

116. Wong MC, Edwards G, Spence SJ, et al. Characterization of catheter-tissue contact force during epicardial radiofrequency ablation in an ovine model. Circ Arrhythm Electrophysiol. 2013;6(6):1222-1228.

117. Okumura Y, Johnson SB, Bunch TJ, Henz BD, O’Brien CJ, Packer DL. A systematical analysis of in vivo contact forces on virtual catheter tip/tissue surface contact during cardiac mapping and intervention. J Cardiovasc Electrophysiol. 2008;19(6):632-640.

118. Kalman JM, Fitzpatrick AP, Olgin JE, et al. Biophysical characteristics of radiofrequency lesion formation in vivo: dynamics of catheter tiptissue contact evaluated by intracardiac echocardiography. Am Heart J. 1997;133(1):8-18.
119. Strickberger SA, Vorperian VR, Man KC, et al. Relation between impedance and endocardial contact during radiofrequency catheter ablation. Am Heart J. 1994;128(2):226-229.

120. Koa-Wing M, Kojodjojo P, Malcolme-Lawes LC, et al. Robotically assisted ablation produces more rapid and greater signal attenuation than manual ablation. J Cardiovasc Electrophysiol. 2009;20(12):1398-1404

121. Azegami K, Satake S, Okishige K, Sasano T, Ohira H, Yamashita K. Monitoring the local electrogram at the ablation site during radiofrequency application for common atrial flutter. Jpn Circ J. 1998;62(8): 559-564.

122. Gepstein L, Hayam G, Shpun S, Cohen D, Ben-Haim SA. Atrial linear ablations in pigs. Chronic effects on atrial electrophysiology and pathology. Circulation. 1999;100(4):419-426.

123. Kumar S, Haqqani HM, Chan M, et al. Predictive value of impedance changes for real-time contact force measurements during catheter ablation of atrial arrhythmias in humans. Heart Rhythm. 2013;10(7):962-969.

124. Sasaki N, Okumura Y, Watanabe I, et al. Relations between contact force, bipolar voltage amplitude, and mapping point distance from the left atrial surfaces of 3D ultrasound- and merged 3D CT-derived images: Implication for atrial fibrillation mapping and ablation. Heart Rhythm. 2015;12(1):36-43

125. Sacher F, Wright M, Derval N, et al. Endocardial versus epicardial ventricular radiofrequency ablation: utility of in vivo contact force assessment. Circ Arrhythm Electrophysiol. 2013;6(1):144-150.

126. Makimoto $\mathrm{H}$, Lin T, Rillig A, et al. In vivo contact force analysis and correlation with tissue impedance during left atrial mapping and catheter ablation of atrial fibrillation. Circ Arrhythm Electrophysiol. 2014;7(1):46-54.

127. Nakagawa H, Kautzner J, Natale A, et al. Locations of high contact force during left atrial mapping in atrial fibrillation patients: electrogram amplitude and impedance are poor predictors of electrodetissue contact force for ablation of atrial fibrillation. Circ Arrhythm Electrophysiol. 2013;6(4):746-753.

128. Tilz RR, Makimoto H, Lin T, et al. In vivo left-ventricular contact force analysis: comparison of antegrade transseptal with retrograde transaortic mapping strategies and correlation of impedance and electrical amplitude with contact force. Europace. 2014; 16(9):1387-1395.

129. Kumar S, Morton JB, Halloran K, et al. Effect of respiration on catheter-tissue contact force during ablation of atrial arrhythmias. Heart Rhythm. 2012;9(7):1041-1047. e1041.

130. Haldar S, Jarman JW, Panikker S, et al. Contact force sensing technology identifies sites of inadequate contact and reduces acute pulmonary vein reconnection: a prospective case control study. Int $J$ Cardiol. 2013;168(2):1160-1166.

131. Reddy VY, Shah D, Kautzner J, et al. The relationship between contact force and clinical outcome during radiofrequency catheter ablation of atrial fibrillation in the TOCCATA study. Heart Rhythm. 2012;9(11): 1789-1795.

132. Neuzil P, Reddy VY, Kautzner J, et al. Electrical reconnection after pulmonary vein isolation is contingent on contact force during initial treatment: results from the EFFICAS I study. Circ Arrhythm Electrophysiol. 2013;6(2):327-333.

133. Natale A, Reddy VY, Monir G, et al. Paroxysmal AF catheter ablation with a contact force sensing catheter: results of the prospective, multicenter SMART-AF trial. J Am Coll Cardiol. 2014;64(7):647-656.

134. Kumar S, Chan M, Lee J, et al. Catheter-tissue contact force determines atrial electrogram characteristics before and lesion efficacy after antral pulmonary vein isolation in humans. J Cardiovasc Electrophysiol. 2014;25(2):122-129.

135. Squara F, Latcu DG, Massaad Y, Mahjoub M, Bun SS, Saoudi N. Contact force and force-time integral in atrial radiofrequency ablation predict transmurality of lesions. Europace. 2014;16(5): 660-667. 
136. Anter E, Tschabrunn CM, Contreras-Valdes FM, Buxton AE, Josephson ME. Radiofrequency ablation annotation algorithm reduces the incidence of linear gaps and reconnection after pulmonary vein isolation. Heart Rhythm. 2014;11(5):783-790.

137. Reichlin T, Lane C, Nagashima K, et al. Feasibility, efficacy, and safety of radiofrequency ablation of atrial fibrillation guided by monitoring of the initial impedance decrease as a surrogate of catheter contact. J Cardiovasc Electrophysiol. 2015;26(4):390-396.

138. Gupta A, Perera T, Ganesan A, et al. Complications of catheter ablation of atrial fibrillation: a systematic review. Circ Arrhythm Electrophysiol. 2013;6(6):1082-1088.
139. Cappato R, Calkins H, Chen SA, et al. Updated worldwide survey on the methods, efficacy, and safety of catheter ablation for human atrial fibrillation. Circ Arrhythm Electrophysiol. 2010;3(1):32-38.

140. Cappato R, Calkins H, Chen SA, et al. Worldwide survey on the methods, efficacy, and safety of catheter ablation for human atrial fibrillation. Circulation. 2005;111(9):1100-1105.

141. Lee G, Sparks PB, Morton JB, et al. Low risk of major complications associated with pulmonary vein antral isolation for atrial fibrillation: results of 500 consecutive ablation procedures in patients with low prevalence of structural heart disease from a single center. JCardiovasc Electrophysiol. 2011;22(2):163-168.

\section{Publish your work in this journal}

Research Reports in Clinical Cardiology is an international, peerreviewed, open access journal publishing original research, reports, editorials, reviews and commentaries on all areas of cardiology in the clinic and laboratory. The manuscript management system is completely online and includes a very quick and fair peer-review system.
Visit http://www.dovepress.com/testimonials.php to read real quotes from published authors. 